\title{
Comparative Analysis on GCMS, Physicochemical and Anti-Microbial Properties of Aerial Parts of Plant Artemisia vulgaris Obtained from Two Different Altitudes
}

\author{
Shiva Pandeya ${ }^{1}$, Anish Pudasaini ${ }^{2}$, Deepak Basyal ${ }^{3}$ \\ ${ }^{1}$ Lecturer, Chemistry, Department of Pharmacy, Maharajgunj Medical College, IOM, TU. Nepal \\ ${ }^{2}$ Department of Pharmacy, Maharajgunj Medical College, IOM, TU. Nepal \\ ${ }^{3}$ Lecturer, Pharmacognosy, Department of Pharmacy, Maharajgunj Medical College, IOM, TU. Nepal
}

\begin{abstract}
The oil obtained by hydro distillation of Artemisia vulgaris using Clevenger apparatus revealed presence of alkanes, oxygenated and non-oxygenated monoterpenes, and sesquiterpenes. The oxygenated monoterpenes were either alcohols or esters, and the oxygenated sesquiterpenes were in the form of acetates and oxides. AVO1 contained 70 different constituents whereas AVO2 contained about 42 different chemical constituents. The physiochemical characters showed that the yield percentage varied from 1.43 to 1.28 , acid value varied from 0.397 to 0.45 and specific gravity varied from 0.878 to 0.902 in AVO1 and AVO2 respectively. Likewise the oil was found to be insoluble in water and fixed oil and soluble in most organic compounds. Volatile oil from both the altitude showed a significant antibacterial and antifungal effect. A large inhibition was seen in S. aureus, E.coli and enterococci species. Both the sample showed antifungal activity against Candida species.
\end{abstract}

Keywords: Artemisia vulgaris, hydrodistilation, essential oil, GCMS, oil yield value, sesquiterpene, organoleptic characters

\section{Introduction}

Since immemorial times medicinal plants have been virtually used in all cultures as a source of medicine. Plants are rich source of effective and safe medicines and from ancient times as a main source of primary health care herbal medicines have been used in many nations. About $80 \%$ of world populations are still dependent on traditional medicines [1]. More than 900 types of precious medicinal plants are said to be found in Nepal among 7000 species of medicinal plants recognized all over the world but only few of them are used for their medicinal value[2]. In developing countries a major part of the total population still uses traditional folk medicine obtained from plant resources for primary health care. According to WHO estimation $80 \%$ of world's population in rural areas rely on herbal traditional medicines as their primary health care [3].This leads in getting growing interest for the study on properties and uses of medicinal plants .It is estimated that only $15-20 \%$ of the population of Nepal - living in and around urban areas have access to modern medicinal facilities, whereas the rest depend on traditional medicines [4].

Nepal is a country with wide range of geographical altitude and climate variations. From various independent researches, it has been found that number and percentage of chemicals vary to a great extent when using plants from different location, altitude, storage conditions and growth period [5]. Thus modern research should focus not only on what chemical the plant possess but in what proportion and how best to cultivate it so as to get maximum yield. Artemisia vulgaris is a magical plant which has been used since ancient times in Nepal mainly as ethno medicine and folk medicine. Volatile oil of Artemisia have been investigated as antimicrobial, antioxidant, cytotoxic and anticonvulsant agents [6].Variation in the volatile components of these plants may occur during plant ontogeny or growth at different altitudes. This study observe chemical variation of Artemisia vulgaris collected from two different altitude and variation in its antimicrobial property.

The active components in the extract of Artemisia vulgaris are flavonoids, coumarins, sesquiterpene, lactones, volatile oils, inulin, and traces of alkaloids. Volatile oil contain about 70 different phytochemicals. The chief compounds of volatile oils include camphor, camphene, $\alpha$-thujone, germacrene $\mathrm{D}, 1,8$ cineole and $\beta$-caryophyllene [7].

Artemisia vulgaris are rhizomatous perennial herbs exhibiting extreme variation in morphology. It has dark green $1-10 \mathrm{~cm}$ long and $3-7.5 \mathrm{~cm}$ wide leaves with the upper surface slightly hairy and the lower surface covered with silvery-white wooly hairs $(<1 \mathrm{~mm}$ long $)[8]$. The leaves on the lower portion of the stem are coarsely segmented, with each segment further dissected. The middle to upper leaves are smaller, but are more coarsely toothed than primary leaves [9].

Volume 8 Issue 11, November 2019

www.ijsr.net

Licensed Under Creative Commons Attribution CC BY 


\section{International Journal of Science and Research (IJSR)}

ISSN: 2319-7064

ResearchGate Impact Factor (2018): 0.28 | SJIF (2018): 7.426

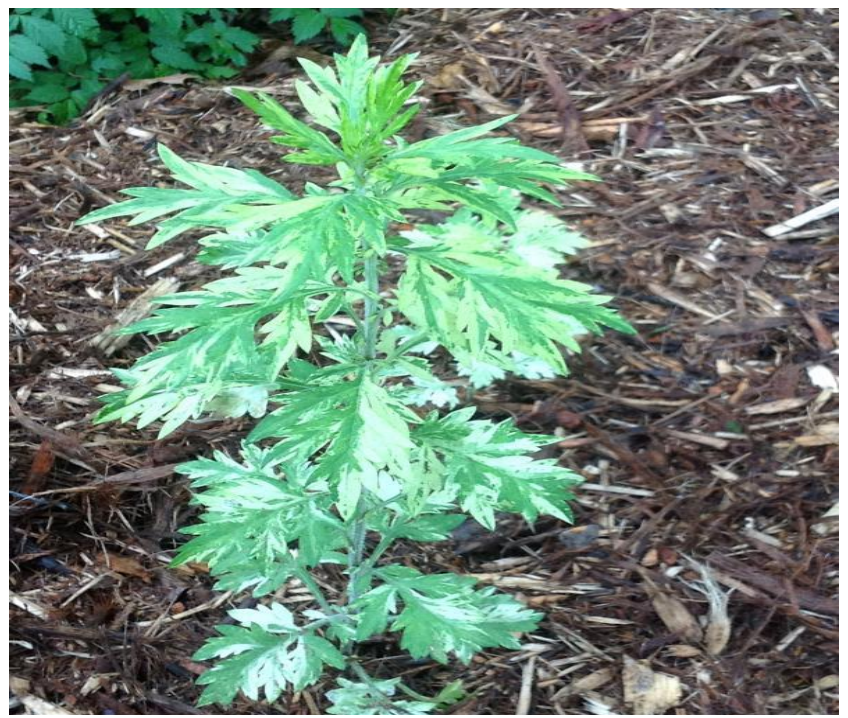

Figure 1: Leaf of Artemisia vulgaris

\section{Experimental section}

\subsection{Sample collection and extraction}

The plant leaves were collected from two different location in September from Kirtipur region of Kathmandu district at an altitude of 1400m above sea level, labelled as AV01 and from Itahari region of Sunsari district at an altitude of $200 \mathrm{~m}$ above sea level, labelled as AV02.

Fresh leaves of both Artemisia vulgaris samples were subjected to essential oil analysis. A $100 \mathrm{~g}$ sample of fresh leaves were mixed with $700 \mathrm{ml}$ distilled water and subjected to hydro distillation in a Clevenger-type distilling apparatus for $2 \mathrm{~h}$. The obtained oil was dried over anhydrous sodium sulphate at $4{ }^{\circ} \mathrm{C}$ and subjected to GC-MS analysis . The test Method was ISO 7609:1985 performed in Department of Plant resources, Nepal Government, Thapathali, and Kathmandu, Nepal.

\subsection{Physiochemical Character Study}

The following physiochemical properties were studied.

\subsubsection{Percentage Yield [10]}

The percentage oil yield was calculated by using following relation

$$
\text { Percentage yield }=\frac{\text { weight of oil }}{\text { Total weight of material used for extraction }} \mathrm{X} 100
$$

\subsubsection{Organoleptic characters}

The organoleptic characters were identified by means of sense of sight, smell and touch.

\subsubsection{Solubility}

A known amount of the solvent was put in a test tube. Then the substance whose solubility is to be determined (oil) was added, a clear layer observed indicates insolubility.

\subsubsection{Specific gravity $[10,11]$}

Specific gravity was determined using specific gravity bottle using the formula

$$
D=\frac{W 2-W 0}{W 1-W 0}
$$

Here,

W0 is the mass of empty specific gravity bottle.

$\mathrm{W} 1$ is the mass of specific gravity bottle filled with water and $\mathrm{W} 2$ is the mass of specific gravity bottle filled with oil

\subsubsection{Acid Value determination [10]}

$5 \mathrm{ml}$ of extracted oil and $25 \mathrm{~mL}$ of neutral alcohol were mixed and heated on a steam bath for 10-15 minutes so as to dissolve the oil. The content was titrated using $0.1 \mathrm{~N} \mathrm{KOH}$ using phenolphthalein as indicator. The acid value was determined by the following formulae

$$
\% \mathrm{I}=\mathrm{V} \quad \mathrm{X} \quad \mathrm{C} \quad \mathrm{X} \quad \frac{56.11}{\mathrm{~m}}
$$

Here,

$\mathrm{V}$ is volume of the $\mathrm{KOH}$ solution used for the titration,

$\mathrm{C}$ is molarity of $\mathrm{KOH}$ and

$\mathrm{m}$ is mass in $\mathrm{g}$ of the test sample.

\subsection{Antimicrobial and Antifungal activity[12]}

The antibacterial and antifungal activity were evaluated through agar cup diffusion method. The media was sterilized in the autoclave at $121{ }^{\circ} \mathrm{C}$ for 21 minutes. Then the sterilized media was cooled and the poured to sterilized petri dish with size $90 \mathrm{~mm}$ diameter and left to solidify. Bacterial suspension was prepared by inoculating loop full of desired microorganisms. The suspension was then swabbed in the media with sterile cotton swab. $20 \mu \mathrm{l}$ of oil was then poured in the bore with help of a micropipette. Three plates were used for each microorganism. This was then refrigerated and kept in incubator for 24 to 48 hours. The Mean zone of Inhibition for both the samples AV01 and AV02 were taken and recorded.

\subsection{Microorganisms used}

Bacterial strains consisted of E.coli, Staphylococcus aureus, Enterococci sp, Psudomonas $S p$ and Salmonella typhii. Similarly fungal stain used was Candida.

\section{Results}

\subsection{Results of physiochemical characteristics}

The results of different physiochemical characters have been reported in Table1, Table 2, Table 3 and report of GCMS analysis have been reported in Table 4 . The antimicrobial test results have been shown in Figure 2 and Figure 3.

Table 1: Organoleptic Characteristics

\begin{tabular}{|c|c|c|}
\hline Characteristics & Sample AV01 & Sample AV02 \\
\hline Colour & Dark Green & Dark Green \\
\hline Odour & Pungent Camphorous & Pungent Camphorous \\
\hline $\begin{array}{c}\text { Appearance at room } \\
\text { temperature }\end{array}$ & Transparent & Transparent \\
\hline
\end{tabular}

\section{Volume 8 Issue 11, November 2019}




\section{International Journal of Science and Research (IJSR) \\ ISSN: 2319-7064 \\ ResearchGate Impact Factor (2018): 0.28 | SJIF (2018): 7.426}

Table 2: Solubility in different solvents

\begin{tabular}{|c|c|}
\hline Characteristics & Sample of AV01 and AV02 \\
\hline Hexane & Soluble at any volume \\
\hline $90 \%$ alcohol & clearly soluble at any volume \\
\hline Chloroform & Soluble at any volume \\
\hline Distilled water & Insoluble \\
\hline Acetone & Slightly soluble \\
\hline Coconut Oil & Insoluble \\
\hline
\end{tabular}

Table 3: Acid Value, Yield percentage and Specific gravity

\begin{tabular}{|c|c|c|}
\hline Parameters & Sample AV01 & Sample AV02 \\
\hline Acid Value & 0.397 & 0.45 \\
\hline Oil Yield Percentage & 1.43 & 1.28 \\
\hline Specific Gravity & 0.8786 & 0.9023 \\
\hline
\end{tabular}

\subsection{GC-MS analysis}

GC-MS result of both the samples oil showed that AVO1 contained 64 different chemical constituents whereas AVO2 contained only 42 constituents. The oil consisted of alkanes, oxygenated and non-oxygenated monoterpenes, and sesquiterpenes. The oxygenated monoterpenes were either alcohols or esters, and the oxygenated sesquiterpenes were in the form of acetates and oxides. Major constituents were identified as sabinene (2.68 and 5.85\%), Eucalyptol (3.59 and $6.02 \%$ ) thujone (5.51 and $3.55 \%$ ) camphor (7.46 and $4.52 \%$ ) borneol (3.36 and 3.12\%) Carophyleene (4.97 and 7.90\%). It was seen that amount of major chemical constituents were more in AVO1 as compared to AVO2. Some of the chemical constituents are as follows

Table 4: List of most common chemical constituents

\begin{tabular}{|c|c|c|c|c|c|}
\hline \multirow{2}{*}{$S . N}$. & \multirow{2}{*}{$\begin{array}{c}\text { Chemical } \\
\text { constituents }\end{array}$} & \multicolumn{2}{|c|}{ AV01 } & \multicolumn{2}{|c|}{ AV02 } \\
\cline { 3 - 6 } & Area \% & Retention time & Area \% & Retention time \\
\hline 1 & Sabinene & 2.68 & 13.617 & 5.85 & 13.617 \\
\hline 2 & Limonene & 1.05 & 16.253 & 0.58 & 16.253 \\
\hline 3 & Eucalyptol & 3.59 & 16.389 & 6.02 & 16.261 \\
\hline 4 & Chrysanthenone & - & - & 1.71 & 19.971 \\
\hline 5 & Thujone( $\beta)$ & 5.51 & 20.066 & 3.55 & 20.059 \\
\hline 6 & S.N. & 3.93 & 20.582 & 6.98 & 20.601 \\
\hline 7 & Camphor & 7.46 & 21.979 & 4.52 & 21.958 \\
\hline 8 & Borneol & 3.36 & 22.998 & 3.12 & 22.993 \\
\hline 9 & Caryophyllene(E) & 4.97 & 34.507 & 7.90 & 34.515 \\
\hline 10 & Viridiflorol & 0.60 & 41.958 & 3.14 & 40.836 \\
\hline 11 & Santolinatriene & 2.95 & 10.631 & 0.41 & 10.634 \\
\hline 12 & Piene $(\alpha)$ & 1.37 & 11.769 & 0.52 & 11.776 \\
\hline 13 & Camphene & 1.53 & 12.438 & 0.74 & 12.445 \\
\hline 14 & Piene $\beta$ & 1.11 & 13.754 & - & - \\
\hline 15 & Myrene & 0.45 & 14.455 & - & - \\
\hline 16 & Bergamal & 0.99 & 17.777 & - & - \\
\hline 17 & Terpinolene & 0.34 & 19.183 & 0.80 & 19.691 \\
\hline 18 & Isoborneal & 0.49 & 22.545 & - & - \\
\hline 19 & Myrtenol & 0.35 & 24.464 & - & - \\
\hline 20 & Cupaene $\alpha$ & 0.73 & 32.585 & 0.80 & 32.591 \\
\hline 21 & Cubenene & 0.56 & 33.397 & 0.52 & 33.206 \\
\hline 22 & Maaliene $\beta$ & 1.05 & 34.066 & 2.74 & 34.076 \\
\hline 23 & Fenchene $\alpha$ & - & - & 0.62 & 12.377 \\
\hline 24 & Intermedeol & 1.28 & 43.896 & 0.96 & 43.841 \\
\hline 25 & Cadinene $\gamma$ & 0.51 & 38.589 & - & - \\
\hline & & & & & \\
\hline
\end{tabular}

\subsection{Antimicrobial results}

Antimicrobial result showed that both samples have a significant zone of inhibition against most of the bacteria and fungi. Out of the 5 strains of antimicrobial agent tested only Pseudomonas was resistant to it while all other showed significant sensitivity. Similarly, both the sample showed antifungal activity against Candida species.

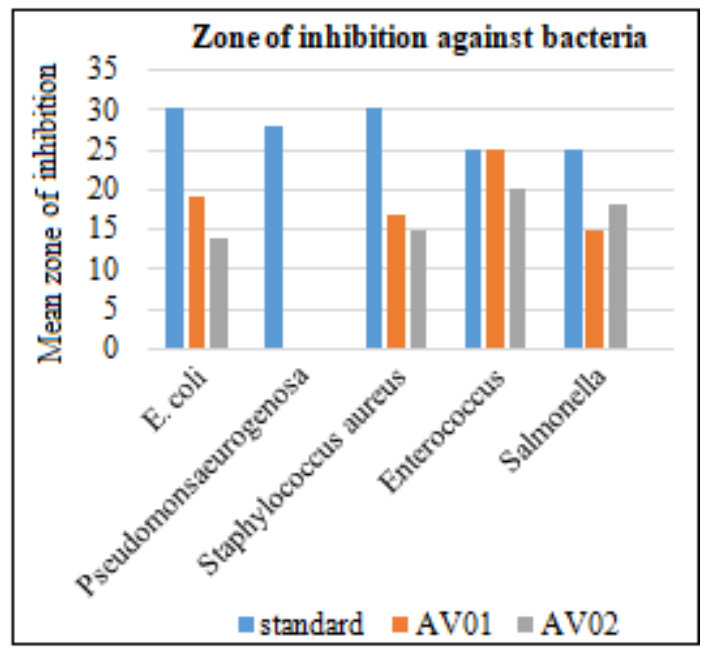

Figure 2: Zone of inhibition against bacteria

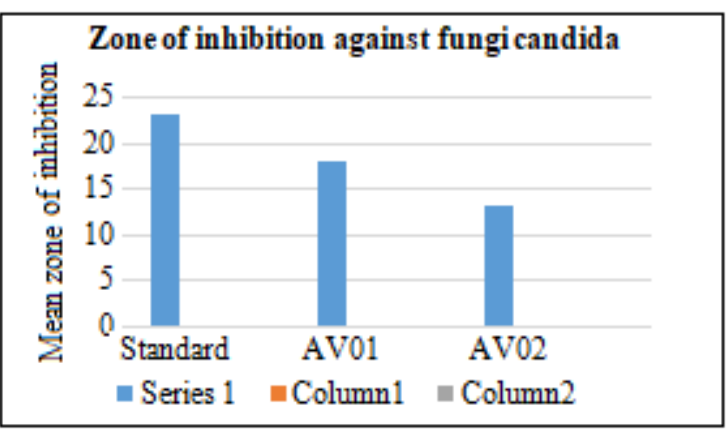

Figure 3: Zone of inhibition against fungi

\section{Discussion and Conclusion}

This work comprised of comparative study of plant description, microscopy, chemical constitution, physiochemical constitution, and anti-bacterial activities of volatile oil obtained from aerial parts of Artemisia vulgaris collected from two different altitudes. The volatile oil of Artemisia vulgaris contains a number of chemical constituents which can be evidenced from GC-MS analysis and shows antibacterial and antifungal activities.

This study reveals that aqueous extracts of aerial part consists of a wide variety of photochemical which differs in altitudes. In this study we found that oil yield percentage by hydro distillation were dependent on a number of factor. The first one being the temperature. It was observed that maximum yield was when temperature was maintained at 60 to 70 degree Celsius. Temperature greater than that showed less yield as well as bumping of the Artemisia-water paste. Another crucial

\section{Volume 8 Issue 11, November 2019}




\section{International Journal of Science and Research (IJSR) \\ ISSN: 2319-7064}

ResearchGate Impact Factor (2018): 0.28 | SJIF (2018): 7.426

factor was size of the plant. Smaller plant were found to be devoid of volatile oil. As we compare the physiochemical studies of these oil the yield percentage of AVO1 was greater with less acid value as compared to AVO2 with less yield percentage and more acid value. Organoleptic characters and solubility were similar whereas specific gravity showed a very minimum difference.

As we focus on the anti-bacterial activity, it reveals that maximum activity is shown by oil obtained from AVO1 as compared to AVO2. The study by Asghari et. al. [12], has also demonstrated that the oil was active against S. aureus, E. coli, Enterococci and L. monocytogenes [13]. The most susceptible microorganisms to both the oil were E. coli, Staphylococcus aureus and Enterococci respectively. Also, Pseudomonas showed least sensitivity and was resistant to both the oil respectively. This demonstrates that the actual anti-bacterial constituent from the oil can be used as a narrow spectrum antibiotic for Staphylococcus aureus, E coli and Enterococcus Species. The study by Gyawali et al[13] , has demonstrated that Artemisia vulgaris was sensitive against S. aureus, E. coli and K. pneumoniae, respectively with MIC value of $125 / 20$, $3.9 / 20$ and $800 \mu \mathrm{g} / 20 \mu \mathrm{l}$, respectively[14]

This plant has many other essential features which needs to be explored. As very less study on this plant has been done, it has a virgin area of research. We recommend further studies on different parts of this plant and the need for isolation of the active chemical constituents along with molding it into formulations for use.

\section{References}

[1] Tiwari S., 2008. Plants: A rich source of herbal medicine. Journal of natural products. Vol. 1(0):27-35.

[2] Chhetri H.P.,2008. Phytochemical and antimicrobial evaluations of some medicinal plants of Nepal. Vol.1:4954.

[3] Joshi B., Lekhak S., Sharma A. , 2009. Antibacterial property of different medicinal plants: Ocimum sanctum, Cinnamomum zeylanicum, Xanthoxylum armatum and Origanum majorana. Kathmandu university journal of science, engineering and technology.Vol. 5(1):143-50.

[4] Asselin H. , 2009. Indigenous use and bio-efficacy of medicinal plants in the Rasuwa District, Central Nepal .Journal of Ethnobiology and Ethnomedicine Vol. 6(2):111-116.

[5] KC S .K., Müller K., 1999. Medicinal plants from Nepal; II. Evaluation as inhibitors of lipid peroxidation in biological membranes. Journal of Ethnopharmacology.Vol. 64(2):135-9.

[6] Bora K.S., Sharma A., 2011. The genus Artemisia: a comprehensive review. Pharmaceutical Biology. Vol. 49(1):101-9.

[7] Govindaraj S., 2008. Mass Propagation and Essential Oil Analysis of Artemisia vulgaris. Journal of Bioscience and bioengineering . Vol. 105:176-83.

[8] Weston L.A., 2005. A Review of the Biology and Ecology of Three Invasive Perennials in New York State:
Japanese Knotweed ( Polygonum cuspidatum ), Mugwort (Artemisia vulgaris) and Pale Swallowwort ( Vincetoxicum rossicum ). Vol.1:53-69.

[9] Writh C.W. ,2002. Artimisia. USA: Taylor and Francis.

[10] Ashok P., Kumud U. ,2010 .Preliminary phytochemical screening and physico-chemical parameters of aerial parts of Artemisia vulgaris. International Journal of Research in Ayurveda and Pharmacy (IJRAP) . Vol. 1(1):206-11.

[11] Ebebini N., 2012. Comparative evaluation of antimicrobial effect of Artemisia vulgaris essential oils extracted from fresh and dried herb. International Journal of Phytomedicines and Related Industries. Vol.4 (2):76-82

[12] Asghari G., Jalali M., Sadoughi E., 2012. Antimicrobial activity and chemical composition of essential oil from the seeds of Artemisia aucheri. Journal of natural pharmaceutical products. Vol.7 (1):11.

[13] Gyawali R., Amatya S., Piya E., Pradhan U.L., Paudyal R., et al.2018. Antibacterial and cytotoxic activities of high altitude essential oils from Nepalese Himalaya. Journal of Medicinal Plants research. Vol. 7(13):73843

[14] Lahlou M., 2004. Methods to study the phytochemistry and bioactivity of essential oils. Phytotherapy research. Vol. 18(6):435-48. 